\title{
Enhancement of the rheological properties of bentonite mud using natural polymers
}

\author{
Muhammed Rufai and Koyejo Oduola * \\ Chemical Engineering Department, University of Port Harcourt, Nigeria.
}

Global Journal of Engineering and Technology Advances, 2021, 07(01), 047-059

Publication history: Received on 01 March 2021; revised on 03 April 2021; accepted on 06 April 2021

Article DOI: https://doi.org/10.30574/gjeta.2021.7.1.0051

\begin{abstract}
This research work focuses on finding more effective polymers that can improve the rheological properties of bentonite mud. Various mud samples were formulated with natural polymers obtained from corn starch, cassava starch, purple potato starch, yellow potato starch and saw dust consisting of different masses which were not treated or purified by any chemical method before and after preparation along with the control mud. Rheology tests were carried out to determine the plastic viscosity, apparent viscosity, yield point, gel strength among others. API standards were followed throughout the experimental study and the result from this investigation showed that increasing the concentration of polymers enhances the mud rheological properties studied at ambient condition, wherein thermal stability was exhibited up till $100^{\circ} \mathrm{C}$. Thus, environmental friendly alternatives have been discovered for drilling fluid additives which are cheap, organic, bio-degradable, non-toxic and easily available
\end{abstract}

Keywords: Starch; Saw dust; Bentonite; Rheology; and Water based mud

\section{Introduction}

The successful completion of an oil well and its cost depend to a considerable extent on the properties of the drilling fluid. The cost of the drilling fluid itself is relatively small, but the choice of the right fluid and maintenance of the right properties while drilling profoundly influence total well costs. For example, the number of rig days required to drill to total depth depends on the rate of penetration of the bit, and on the avoidance of delays caused by caving shale's, stuck drill pipe, loss of circulation, etc., all of which are influenced by the properties of the drilling fluid. In addition, the drilling fluid affects formation evaluation and the subsequent productivity of the well.

It follows that the selection of a suitable drilling fluid and the day-to-day control of its properties are the concern not only of the mud engineer, but also of the drilling supervisor, the drilling foreman, and drilling, logging and production engineers. Drilling and production personnel do not need a detailed knowledge of drilling fluids, but they should understand the basic principles governing their behavior, and the relation of these principles to drilling and production performance [1].

A major component in drilling operation success is drilling fluid performance. The cost of searching for hydrocarbon reserves becomes more expensive when drilling occurs offshore, in deep water, and in hostile environments. These drilling environments require fluids that excel in performance.

Measuring fluid performance requires the evaluation of all key drilling parameters and their associated cost. Simply stated, the effectiveness of a fluid is judged by its influence on overall well cost [2]. Temperature and pressure increase dramatically with the depth of the well. Oil and gas fields with temperatures and pressures above $230^{\circ} \mathrm{C}\left(440^{\circ} \mathrm{F}\right)$ and $160 \mathrm{MPa}$ (23 000psi), respectively, have been reported [3, 4]. Although there is not a universal definition, the term high

\footnotetext{
${ }^{*}$ Corresponding author: Oduola MK

Department of Chemical Engineering, University of Port Harcourt, Nigeria.

Copyright (C) 2021 Author(s) retain the copyright of this article. This article is published under the terms of the Creative Commons Attribution Liscense 4.0.
} 
pressure-high temperature (HPHT) is used by operators to indicate downhole temperatures in excess of $150^{\circ} \mathrm{C}$ (approximately $300^{\circ} \mathrm{F}$ ) and pressures above $103 \mathrm{MPa}(15000 \mathrm{psi})$ are referred to as ultra-or extreme-HPHT (xHHT or $\mathrm{X}$-HPHT) wells [5]. In addition to temperature and pressure, a third parameter that is used to identify HPHT conditions is the so-called geothermal gradient [5]. In this regard, geothermal gradients above $0.046 \circ \mathrm{C} / \mathrm{m}\left(0.014^{\circ} \mathrm{F} / \mathrm{ft}\right)$ are a good indication of HPHT environments in which thermal effects merit serious consideration. The wellbore temperature during drilling is a complex function of wellbore geometry, wellbore depth, penetration rate, flow rate, duration of the shut-in intervals, pump and rotary inputs, fluid and formation properties, and geothermal gradients [6].

The design and production of drilling fluid in oil and gas industry over the years have been faced with the challenges of either importing the materials to produce and or in some cases imported, already designed and produced drilling mud. In this case, industry in this sector adjust the properties of the drilling fluid which aid the right types of additives which are also imported to suit the formation requirement of the area to be drilled. This has not allowed them to compete effectively with their foreign counterpart. Therefore, research into this area is critical. Nigeria is replete with natural resources in various forms, thus research to find how our own raw materials can be used or the availability of suitable substitutes which can be developed and examined within our country for educational and technological advancement of Nigeria is essential [7, 8].

Besides, the petroleum industry bill that was proposed seeks to achieve the promotion of the development of local content in the oil and gas industry as one of its major goal, with this in view the need for the development of local additives as substitute for foreign additives is paramount in order to reduce over reliance on the imported additives which hitherto cut down the cost of drilling operation $[9,10,11,12,13,14]$.

In this study we therefore seek to formulate drilling mud using locally derived materials as a mixture of locally selected starch from plants and bentonite which is readily available in commercial quantity as fluid loss additives and viscosifier. Furthermore, the influence of various additives on the performance of drilling fluid with a bid to making the drilling operation smooth, cost effective and efficient.

\section{Material and methods}

\subsection{Materials and Equipment}

In this research work, the additives employed with their functions in the formulation of the water based drilling fluids were Barite as weighting material, bentonite as viscosifier and filtration control material, starch and saw dust as rheological control materials, Distilled water as continuous base, Soda Ash $\left(\mathrm{Na}_{2} \mathrm{CO}_{3}\right)$ as hardness material and caustic soda as $\mathrm{pH}$ control material $\mathrm{NaOH}$.

The API designed Six-Speed Rotational Viscometer used was manufactured in accordance with specifications. It is used to measure the rheological properties (plastic viscosity, apparent viscosity, yield points and gel strength) of mud samples and before using it for the experiment, the viscometer was calibrated according to the operating manual SixSpeed Rotational Viscometer [15]. A mud balance was used to measure the density (weight) of drilling fluid, cement or any type of liquid after mixing all the drilling fluids additives.

The aging cell assembly was employed to simulate the properties of drilling mud at bottom-hole conditions from the surface conditions as the properties at the surface do not in any way give true picture of bottom-hole conditions [16]. To initiate the aging process of the water based drilling fluid, fan aging cell assembly was used. The aging cell had a capacity of holding $500 \mathrm{ml}$. of fluid within it. The maximum operating condition of this aging cell was 175 oC and 125 psi.

\subsection{Design Concept}

This section presents a culmination summary of the results from extensive testing that demonstrates the optimal combination of additives that are needed to design water-based mud. Mixing and addition conditions were established and controlled to optimize additive performance and to ensure a good comparison between formulations. The rheological properties were measured at $25^{\circ} \mathrm{C}$ and $100^{\circ} \mathrm{C}$. API low temperature/low-pressure fluid loss as described was used as a screening tool to determine which fluids would be selected for fluid-loss evaluation. The concentration of additives and their functions in the drilling fluid as used for this work were patterned as follows (Table 1). 
Table 1 Standard Mud Preparation composition

\begin{tabular}{|l|l|l|l|}
\hline Additives & Concentration & $\begin{array}{l}\text { Percentage of Additives per } \\
\mathbf{3 5 0 m} \text { of water }\end{array}$ & Function(s) \\
\hline Water & $350 \mathrm{ml}$ & NA & Base fluid \\
\hline Bentonite & $22.5 \mathrm{~g}$ & $22.5 \%$ & Filtration Control and viscosifer \\
\hline Caustic soda & $0.35 \mathrm{~g}$ & $0.35 \%$ & Alkalinity control \\
\hline Soda ash & $0.35 \mathrm{~g}$ & $0.35 \%$ & Calcium ion removal \\
\hline Barite & $76.8 \mathrm{~g}$ & $76.8 \%$ & Weighting agent \\
\hline Saw dust & $(2 \%, 4 \%, 6 \%, 8 \%, 10 \%)$ & NA & Filtration Control and viscosifer \\
\hline Cassava starch & $(2 \%, 4 \%, 6 \%, 8 \%, 10 \%)$ & NA & Filtration Control and viscosifer \\
\hline Yellow potato starch & $(2 \%, 4 \%, 6 \%, 8 \%, 10 \%)$ & NA & Filtration Control and viscosifer \\
\hline Purple potato starch & $(2 \%, 4 \%, 6 \%, 8 \%, 10 \%)$ & NA & Filtration Control and viscosifer \\
\hline Corn starch & $(2 \%, 4 \%, 6 \%, 8 \%, 10 \%)$ & NA & Filtration Contro and viscosifer \\
\hline
\end{tabular}

\subsection{Sample Preparation and Sampling Techniques}

\subsubsection{Cassava Starch Preparation}

Local cassava variety was purchased in IITA Onne, Rivers State. Some of the cassava roots were peeled and cut into smaller sizes. The reduced sizes of the cassava were washed and soaked with distilled water and ground using electric grinder to produce a paste. Reasonable quantity of water was added to the paste and then poured into porous cloth and squeezed tightly to collect the filtrate in a container. The filtrate was then allow to settle for 24 hours and suspended water was decanted whiles the solid starch was then spread in a tray under direct sunlight for some days to remove the moisture content. The dried starch was grounded with mortar and pestle which later sieved to obtain a smooth powder and stored in a container as fluid loss agent additives for drilling mud preparation.

\subsubsection{Potato Starch Preparation}

The potato tubers were purchased at Oil mill market, Obi/Akpor LGA in Rivers State Nigeria. Sweet Potato (Purple and yellow varieties) were peeled, washed and ground into small sizes. The reduced sizes of the potato were washed and soaked with distilled water and ground using electric grinder to produce a paste. Reasonable quantity of water was added to the paste and then poured into porous cloth and squeezed tightly to collect the filtrate in a container. The filtrate was then allow to settle for 24 hours and suspended water was decanted in an environmental friendly ways whiles the solid starch was then spread in a tray under direct sunlight for some days to remove the moisture content. The dried starch was grounded with mortar and pestle which later sieved to obtain a smooth powder and stored in a container as fluid loss agent additives for drilling mud preparation.

\subsubsection{Preparation of Corn flour starch}

Corn kernels were removed from the cob, washed and soaked them in a large bowl for 4 days for inhibition while changing the water every 24 hours. They were then thoroughly rinsed with fresh water and crushed by electric grinder until extremely smooth paste was obtained. Using a sieve to run the blended corn through with lots of water and then discard the chaff in an environmental friendly manner. Leave the sieved corn to rest for 10 hours for the solid part to settles at the bottom and the excess water can be decanted. Strain further using normal fabric and then spread on the tray under direct sunlight for some days to dry and then stored in a polythene bag and appropriately labeled for use.

\subsubsection{Preparation of saw dust Particles}

Saw dust particles were used as a key additive for rheology control. It was used instead of the chemicals such as carboxyl methyl cellulose (CMC), PAC-L, PAC-R, etc. to enhance rheological properties of bentonite mud [13].

- $\quad$ Melina saw dust was gotten from saw mill

- $\quad$ The saw dust was dried for 10 days

- $\quad$ The dried saw dust was then sieved with sieve size of $0.5 \mathrm{~mm}$.

- $\quad$ The sieved saw dust was properly packaged in a polythene bag for use. 


\subsubsection{Drilling mud formulation}

The bentonite used in this experiment was obtained from MI Swaco at F.O.T, Onne oil and Gas Free Zone Eleme Local Government Area, Rivers State. Spatula was used to transfer 22.5g of the bentonite on an electronic balance while $500 \mathrm{ml}$ measuring cylinder was used to measure $350 \mathrm{ml}$ of distill water according to API requirement for preparing drilling fluid. The measured water, $350 \mathrm{ml}$ was transferred into the steel cup of the multi - mixer and weighed bentonite was added. The mixture of the bentonite and water was vigorously agitated with the aid of multi mixer powered to rotate for about 20 minutes, until homogenous mixture is obtained. The mixture was then allowed to stand for 24 hours for the proper hydration and swelling of bentonite. This represents mud without treatment. The drilling mud samples were subsequently treated with chemical additives in different proportion and thereafter formulated as shown in Table 1 above in the absence and presence of difference concentration $(2 \%, 4 \%, 6 \%, 8 \%$, and $10 \%)$ of saw dust, cassava starch, potato starch and corn starch. As the additives have been properly measured into the mixer steel cup containing the mud sample, it was left for 60 minutes under stirring condition to react well with the mud for complete uniformity. The mud balance was used to measure the density of the mud, the dial readings of the various samples were taking by the use of viscometer at readings of 600, 300, 200, 100, 60, 30 and 3rpm to evaluate the rheological properties. Also, 10 seconds and 10 minutes gel strength values were recorded. $\mathrm{pH}$ meter was used to measure the $\mathrm{pH}$ of the formulated drilling mud.

\subsection{Rheological Properties determination}

\subsubsection{Determination of viscosity}

The viscosity of a fluid is defined as its resistance to flow. The desired viscosity for a particular drilling operation is influenced by several factors, such as temperature, pressure of the system, shear rate, etc. The indicated viscosity as obtained by any instrument is valid only for that rate of shear and will differ to some degree when measured at a different rate of shear. For field applications, a qualitative viscosity measure can be obtained by the Marsh funnel. The funnel viscosity is the time in seconds for 1 quart of mud to pass through the Marsh funnel, expressed as seconds per quart. To determine the viscosity using the Marsh funnel, hold the funnel in an upright position and place a finger over the outlet. Pour the test sample, which has just been taken from near the pump suction end of the mud pit, through the screen into top of the funnel until the level of drilling mud just reaches the bottom of the screen. Place a cup under the funnel outlet. Remove the finger from the outlet and time the number of seconds for one quart of fluid to flow from the funnel into the cup. The number of seconds is recorded as the funnel viscosity. If available, a stopwatch should be used for measuring the time. The usual range of Marsh funnel viscosities for good effective bentonite mud is 32 seconds to 38 seconds per quart; for polymer mud, funnel viscosities of 40 seconds to 80 seconds per quart are reasonable. For comparison, the funnel viscosity of fresh water is 28 seconds per quart at 68 degrees F. For laboratory, a direct indicating rotational multi-speed instrument, has become the standard, allowing the measurements of rheological properties such as plastic viscosity, apparent viscosity, yield point, and gel strength [17].

The agitated mud samples were poured into viscometer cup at room temperature and rotor was immersed to the scribed line. Throughout the laboratory experiment each mud sample assumed the volume of $350 \mathrm{ml}$ and the dial readings of these samples were taking by the use of rotational fan viscometer at readings of $600,300,200,100,60,30$, and $3 \mathrm{rpm}$. The viscosity properties of the formulated mud such as the plastic viscosity, apparent viscosity, yield point and gel strength were computed using equations 1,2 and 3.

\subsubsection{Determination of Plastic Viscosity}

The value of plastic viscosity is derived from two readings from viscometer (600 and $300 \mathrm{rpm}$ ). The low value of plastic viscosity is desirable as the drilling process is rapid due to the low viscosity of the mud existing at the bit. The high values indicate the existence of excess solids or viscous base fluid. By dilution, we can lower the value of plastic viscosity.

$P V($ in centipoise $)=\theta 600-\theta 300$

Where $\theta 600$ is the reading of the viscometer at speed $600 \mathrm{rpm}$ and $\Theta 300$ is the reading of the viscometer at speed 300 rpm.

\subsubsection{Determination of apparent Viscosity}

The viscosity of a fluid is measured at a given shear rate at a fixed temperature. In order for a viscosity measurement to be meaningful, the shear rate must be stated or defined. It is a rheological property calculated from viscometer readings performed by a mud engineer on drilling fluid. It is normally abbreviated as AV (Sometimes denoted). It is expressed in 
cp (centipoise). These calculations and test help the mud engineer to develop and maintain the properties of the drilling fluid to the specifications required [18]. It was measured by dividing at viscometer dial reading at $600 \mathrm{rpm}$ by 2.

$\mathrm{AV}($ in centipoise $)=1 / 2 \theta 600$

\subsubsection{Determination of Yield Point}

The yield point is the resistance of the fluids to initial flow or the stress required to start fluid movement. The higher value of yield point is desirable as the drilling mud had the ability to carry cuttings better than fluid with the same density but with lower yield point [18]. The yield point of the prepared sample was also calculated in $1 \mathrm{~b} / 100 \mathrm{ft} 2 \mathrm{by}$ subtracting the calculated value of the Plastic viscosity of the prepared sample in centipoise from the $300 \mathrm{rpm}$ reading.

$\mathrm{YP}(1 \mathrm{~b} / 100 \mathrm{ft} 2)=\theta 300-\mu \mathrm{P}$

\section{Results and discussion}

The result of the experiment obtained have been compared with the American petroleum Institute (API) standard specification for drilling mud and these specifications are for all the montmorillonite clay family as contained in API practices 13A [19]. Table 2 shows the API 13A specification requirements for assessing the quality of water based drilling mud necessary to ensure optimum drilling.

Table 2 API Standard Specification for Drilling Bentonite Mud [10]

\begin{tabular}{|l|l|}
\hline Drilling Fluid Property & Numerical Value Requirement \\
\hline Mud density (1b/gal) & $8.65-9.60$ \\
\hline Viscometer dial reading at 600rpm & $30 \mathrm{cp}$ \\
\hline Plastic viscosity (cp) & $8-10$ \\
\hline Yield point (Ib/100ft ${ }^{2}$ ) & 3 x plastic viscosity \\
\hline Fluid loss (Water) & $15.0 \mathrm{ml}$ maximum \\
\hline pH level & 9.5 min -12.5 max \\
\hline
\end{tabular}

\subsection{Rheology Test}

Rheology describes the flow properties of a drilling mud necessary for the removal of cuttings while drilling.

Table 3 and 4 present a total account of results from the rheological test conducted at the laboratory on the bentonite samples giving details of the rheometer dial readings. From the dial readings, the plastic viscosity (PV), apparent viscosity (AV) and yield point (YP) were calculated using equations 1, 2 and 3 respectively.

The experiment was conducted at room temperature which was considered to be $25^{\circ} \mathrm{C}$ and elevated temperature at $100^{\circ} \mathrm{C}$ but in the course of experiment, it is not certain that the temperature remains constant.

\subsection{Effect of Polymer Concentration on Plastic Viscosity of Bentonite Mud}

Plastic viscosity PV is defined as the resistance of a fluid to flow. API maximum requirement for plastic viscosity for bentonite mud is $8 \mathrm{cp}-10 \mathrm{cp}$. The bentonite mud used for this study had a PV of 4cp which is below the API standard requirement and consequently it was beneficiated with additives to improve its property. The five used polymers are corn starch, cassava starch, purple potato starch, yellow potato starch and saw dust. But after adding the polymers to the blank mixture in the conc. of $2 \%, 4 \%, 6 \%, 8 \%$ and $10 \%$, all the mud properties were enhanced. It was found that, there is increase in PV but with different values depending on the polymer type and solids by weight and as shown in Fig 1.

The local starch modified muds exhibited better performance than saw dust modified muds. Corn starch, yellow potato starch and purple potato starch with $10 \%$ of polymer each gives the highest value of PV than others. Bentonite muds treated with corns starch, cassava starch, purple and yellow potato starch performed best at 6\% polymer concentration while bentonite mud treated with saw dust was at its best at $10 \%$ presence. However, for the local starches, optimum 
concentration ranged between $4 \%-8 \%$ for corn starch, $6 \%-10 \%$ for cassava starch, $6 \%-10 \%$ for purple potato starch, $2 \%-8 \%$ for yellow potato starch. It can be said that we can use any of these polymers to enhance the plastic viscosity of bentonite mud

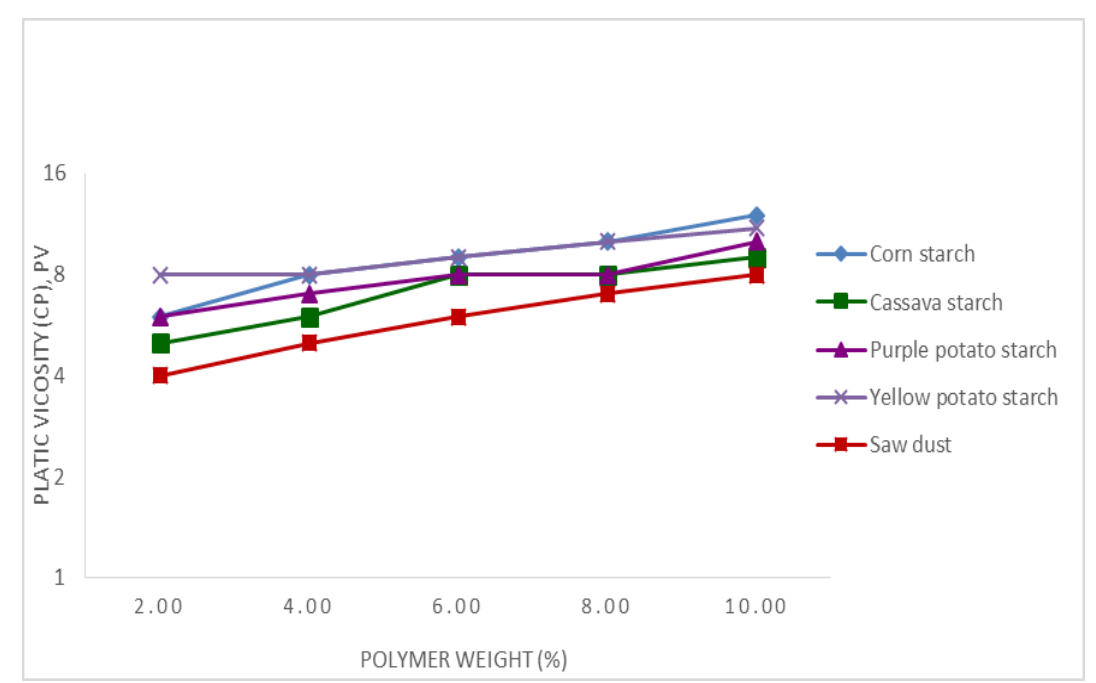

Figure 1 Variation of plastic viscosity with concentration of polymer at room temperature

\subsection{Effect of Polymer Concentration on Yield Point of Bentonite Mud}

Yield point is a measure of the attractive force among colloidal particles in a drilling mud. API standard recommends that, yield point of any drilling mud should have a numerical value of 3PV and not exceeding the value of 50 for optimal drilling fluid performance as shown in Table 3. Unlike the control bentonite mud used for this study had a YP of 10 $\mathrm{lb} / 100 \mathrm{ft} 2$ which is below the value specification recommended by API standard for drilling operation and hence there is need to beneficiate to enhance its properties. In this section, the effect of increasing the concentration of polymers on the yield point YP of bentonite muds have been studied. It can be seen from Fig 2 that the YP rise gradually but with different values depending on the polymer type as illustrated in Table 3, with the highest values recorded with cornstarch and yellow potato starch modified mud at $10 \%$ polymer concentration. The mud sample with the concentration of polymers in the range between $4 \%-8 \%$ for corn starch, $6 \%-10 \%$ for cassava starch, $6-10 \%$ for purple starch, $2 \%-8 \%$ for yellow potato starch, $8 \%-10 \%$ for saw dust is a potential optimum operation for the performance of the mud sample.

Table 3 Rheological parameters of Bentonite mud with Beneficiation after 24hours of Aging at room temperature

\begin{tabular}{|c|c|c|c|c|c|c|c|c|c|c|c|}
\hline $\begin{array}{l}\text { Polymer } \\
\text { wt(\%) }\end{array}$ & $\theta 600$ & $\theta 300$ & $\theta 200$ & $\theta 100$ & $\theta 6$ & $\theta 3$ & AV & PV & YP & $\begin{array}{l}\text { Gs at } \\
10 \mathrm{sec}\end{array}$ & $\begin{array}{l}\text { Gs at } \\
10 \mathrm{~min}\end{array}$ \\
\hline \multicolumn{12}{|c|}{ Bentonite mud (BM) without polymer } \\
\hline 0.00 & 18 & 14 & 10 & 8 & 6 & 4 & 9 & 4 & 10 & 3 & 5 \\
\hline \multicolumn{12}{|c|}{ Bentonite mud with corn starch } \\
\hline 2.00 & 36 & 30 & 25 & 20 & 15 & 10 & 18 & 6 & 24 & 5 & 12 \\
\hline 4.00 & 40 & 32 & 28 & 24 & 20 & 15 & 20 & 8 & 24 & 10 & 16 \\
\hline 6.00 & 45 & 36 & 32 & 28 & 24 & 20 & 22.5 & 9 & 27 & 14 & 20 \\
\hline 8.00 & 50 & 40 & 36 & 30 & 26 & 22 & 25 & 10 & 30 & 18 & 26 \\
\hline 10.00 & 60 & 48 & 40 & 35 & 30 & 24 & 30 & 12 & 36 & 22 & 32 \\
\hline \multicolumn{12}{|c|}{ Bentonite mud treated with cassava starch } \\
\hline 2.00 & 25 & 20 & 16 & 10 & 6 & 5 & 12.5 & 5 & 15 & 5 & 8 \\
\hline 4.00 & 30 & 24 & 20 & 15 & 8 & 6 & 15 & 6 & 18 & 6 & 10 \\
\hline
\end{tabular}




\begin{tabular}{|c|c|c|c|c|c|c|c|c|c|c|c|}
\hline 6.00 & 36 & 28 & 24 & 20 & 14 & 8 & 18 & 8 & 20 & 8 & 14 \\
\hline 8.00 & 40 & 32 & 28 & 22 & 16 & 12 & 20 & 8 & 24 & 10 & 16 \\
\hline 10.00 & 45 & 36 & 32 & 26 & 22 & 18 & 22.5 & 9 & 27 & 14 & 20 \\
\hline \multicolumn{12}{|c|}{ Bentonite mud treated with purple potato starch } \\
\hline 2.00 & 28 & 22 & 18 & 14 & 10 & 8 & 14 & 6 & 16 & 8 & 10 \\
\hline 4.00 & 35 & 28 & 22 & 16 & 12 & 10 & 17.5 & 7 & 21 & 10 & 12 \\
\hline 6.00 & 40 & 32 & 26 & 20 & 14 & 10 & 20 & 8 & 24 & 10 & 14 \\
\hline 8.00 & 44 & 36 & 28 & 22 & 16 & 12 & 22 & 8 & 28 & 12 & 16 \\
\hline 10.00 & 48 & 38 & 30 & 24 & 18 & 14 & 24 & 10 & 28 & 14 & 20 \\
\hline \multicolumn{12}{|c|}{ Bentonite mud treated with yellow potato starch } \\
\hline 2.00 & 38 & 30 & 24 & 20 & 14 & 8 & 19 & 8 & 22 & 8 & 14 \\
\hline 4.00 & 40 & 32 & 28 & 22 & 16 & 12 & 20 & 8 & 24 & 10 & 16 \\
\hline 6.00 & 45 & 36 & 30 & 25 & 20 & 14 & 22.5 & 9 & 27 & 12 & 18 \\
\hline 8.00 & 50 & 40 & 35 & 30 & 25 & 18 & 25 & 10 & 30 & 14 & 20 \\
\hline 10.00 & 55 & 44 & 38 & 34 & 30 & 25 & 27.5 & 11 & 33 & 18 & 24 \\
\hline \multicolumn{12}{|c|}{ Bentonite mud treated with saw dust } \\
\hline 2.00 & 20 & 16 & 12 & 8 & 5 & 4 & 10 & 4 & 12 & 4 & 6 \\
\hline 4.00 & 25 & 20 & 16 & 10 & 6 & 6 & 12.5 & 5 & 15 & 6 & 8 \\
\hline 6.00 & 30 & 24 & 20 & 14 & 10 & 8 & 15 & 6 & 18 & 8 & 10 \\
\hline 8.00 & 35 & 28 & 22 & 16 & 12 & 10 & 17.5 & 7 & 21 & 10 & 12 \\
\hline 10.00 & 40 & 32 & 26 & 20 & 14 & 10 & 20 & 8 & 24 & 10 & 14 \\
\hline
\end{tabular}

From Table 3, yield points in all the formulated mud samples varied from high in corn starch, moderate in both potato starch and low in saw dust at any given polymer concentration. Yield point shows the ability of drilling mud to carry cuttings to surface, therefore a reduction in its numerical value renders the mud ineffective in carrying out its role as a cutting transporter.

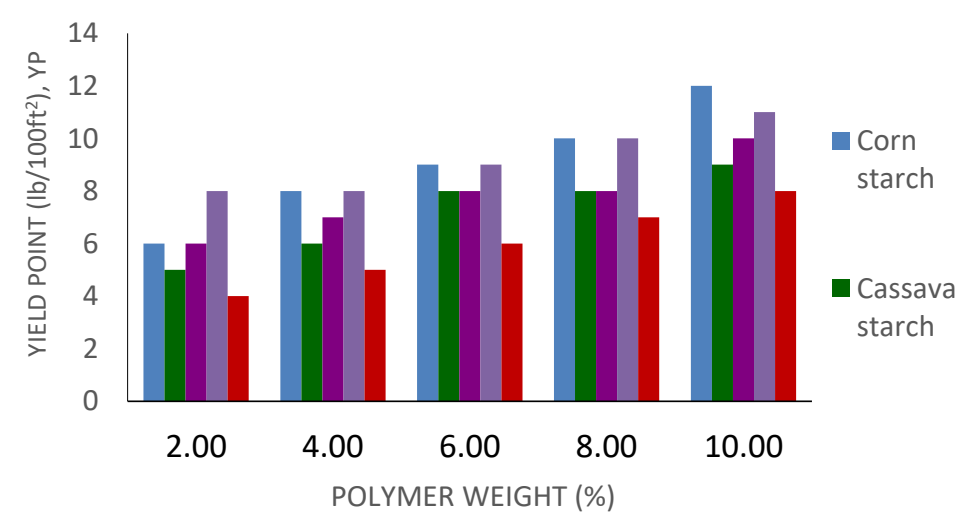

Figure 2 Variation of yield point with concentration of polymer at room temperature 


\subsection{Effect of Polymer Concentration on Apparent Viscosity of Bentonite Mud}

Apparent viscosity is the viscosity at 600 rpm reading and is the reflection of both the plastic viscosity and yield point. This shows that a decrease in both of them will result in a decrease in the apparent viscosity (AV). The value of AV helps the mud engineer to develop and maintain the properties of the drilling mud to the specification required. Fig 3 shows the effect of polymer concentration on the apparent viscosity where it gives an indication that an increase in the various polymer concentrations resulted in the increase in apparent viscosities of bentonite samples. The control mud with $9 \mathrm{cp}$ as AV does not conformed to the API standard requirement for using drilling grade bentonite mud which indicates that mud should have a minimum AV value in the range of $12-15 \mathrm{cp}$. In this section the effect of polymer concentration on the AV have been studied and it was found that apparent viscosity recorded increased from the range of $9 \mathrm{cp}-30 \mathrm{cp}$ for mud sample treated with corn starch, $9 \mathrm{cp}-22.5 \mathrm{cp}$ for mud sample treated with cassava starch, $9 \mathrm{cp}-24 \mathrm{cp}$ for mud samples treated with purple potato starch, $9 \mathrm{cp}-27.5 \mathrm{cp}$ for mud sample treated with yellow potato starch and $9 \mathrm{cp}-20 \mathrm{cp}$ for mud sample treated with saw dust for polymer concentration in the range $0-10 \%$.

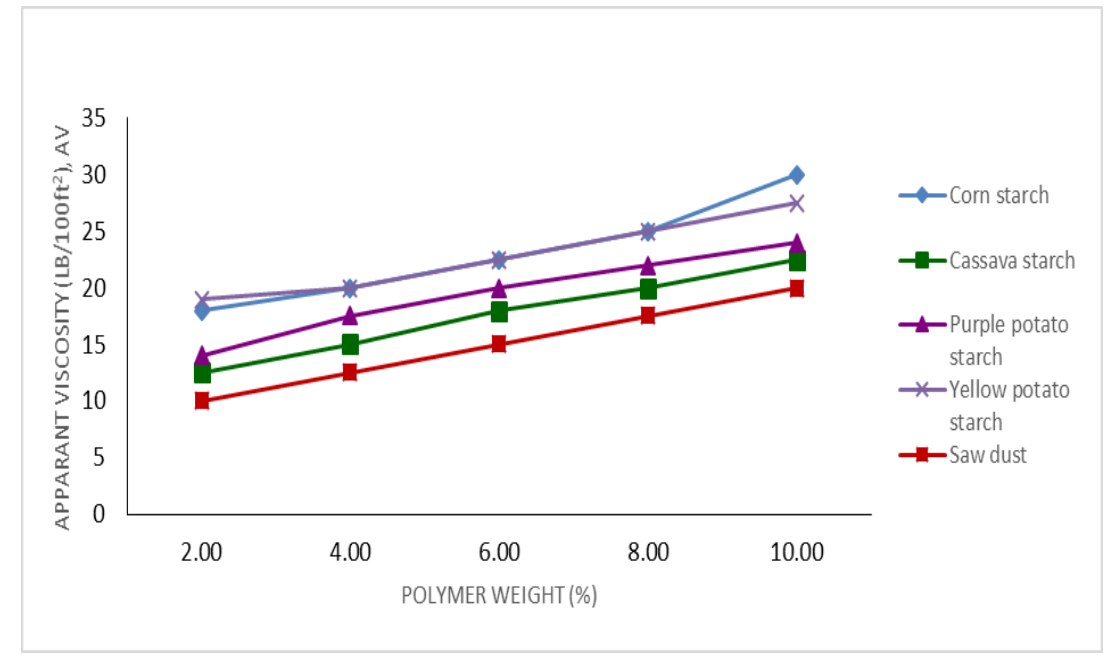

Figure 3 Variation of apparent viscosity with concentration of polymer at room temperature

\subsection{Effect of Polymer Concentration on the Gel strength of Bentonite Mud}

The gel strength is one of the important factors in drilling fluid properties because it gives the drilling fluid the ability to suspend drill solids and weighting material when circulation is stopped. In this section, the effect of increasing the concentration of polymers on gel strength in the mud samples has been studied.

It is evident from Fig. 4 that the gel strength gradually increased with the concentration of polymers. The effect differs among polymers where corn starch has the highest effect on the gel strength than other polymers. In the absence of polymers, Table 3 shows value of $3 \mathrm{lb} / 100 \mathrm{ft} 2$ at 10 second and value of $5 \mathrm{lb} / 100 \mathrm{ft} 2$ for the gel strength at $10 \mathrm{minutes}$ for bentonite mud. It is obvious, that, after formulation with polymers, the gel strength is improved. However, the lower the gel strength, the lower the pump pressure needed for circulation to start up after rest. Lower pump pressure would mean lower energy consumption and reduced frequency of pump break down when the drilling mud has a high gel strength it will require high pump pressure in order to break the static bonds after the mud has been static for a long time.

\subsection{Effect of Temperature on Rheological properties of Bentonite Mud formulated with Polymers}

Elevated temperature has a significant effect on rheological properties. Figs 5 to 9 show the effect of temperature on the various rheological properties of bentonite mud formulated with polymer at $100^{\circ} \mathrm{C}$. As observed, good rheological properties were still obtained particularly for the mud with $6 \mathrm{gm}$ of polymers except saw dust. This can be attributed to the deterioration of the polymer bonds in the mud sample as temperature increased from $25^{\circ} \mathrm{C}$ to $100^{\circ} \mathrm{C}$. From Figs 5 to 8 and Table 4, it can be seen that all mud samples formulated with corn starch (2\%, 4\%, 6\%, 8\% and 10\%) decreased in their rheological properties from $25^{\circ} \mathrm{C}$ to $100^{\circ} \mathrm{C}$. Mud samples with cassava starch, purple potato starch, yellow potato starch and saw dust also showed the same pattern of decrease in $\mathrm{AV}, \mathrm{PV}, \mathrm{YP}, \mathrm{Gs}$ at $10 \mathrm{sec}$ and Gs at $10 \mathrm{~min}$ at $100^{\circ} \mathrm{C}$ at $6 \%$ for all polymers except saw dust. Therefore, the results obtained have further buttressed the fact elevated temperature has a huge effect on the rheological properties of bentonite mud sample formulated with polymers. 
Table 4 Rheological Parameters of 22.5g of Bentonite Mud with Beneficiation after 24hours of Aging at $100^{\circ} \mathrm{C}$

\begin{tabular}{|c|c|c|c|c|c|c|c|c|c|c|c|}
\hline $\begin{array}{l}\text { Polymer } \\
\text { wt (\%) }\end{array}$ & $\theta 600$ & $\theta 300$ & $\theta 200$ & $\theta 100$ & $\theta 6$ & $\theta 3$ & $\mathbf{A V}$ & PV & YP & $\begin{array}{l}\text { Gs at } \\
10 \text { sec }\end{array}$ & $\begin{array}{l}\text { Gs at } \\
10 \mathrm{~min}\end{array}$ \\
\hline \multicolumn{12}{|c|}{ Bentonite mud treated with corn starch } \\
\hline 2.00 & 20 & 16 & 12 & 8 & 4 & 4 & 10 & 4 & 12 & 4 & 10 \\
\hline 4.00 & 30 & 24 & 18 & 14 & 10 & 6 & 15 & 6 & 18 & 6 & 16 \\
\hline 6.00 & 35 & 28 & 24 & 20 & 16 & 12 & 17.5 & 7 & 21 & 10 & 20 \\
\hline 8.00 & 40 & 32 & 28 & 24 & 20 & 14 & 20 & 8 & 24 & 12 & 20 \\
\hline 10.00 & 50 & 40 & 34 & 28 & 24 & 18 & 25 & 10 & 30 & 16 & 24 \\
\hline \multicolumn{12}{|c|}{ Bentonite mud treated with cassava starch } \\
\hline 2.00 & 15 & 12 & 10 & 8 & 4 & 4 & 7.5 & 3 & 9 & 2 & 4 \\
\hline 4.00 & 20 & 16 & 12 & 10 & 6 & 5 & 10 & 4 & 12 & 4 & 6 \\
\hline 6.00 & 30 & 24 & 20 & 16 & 12 & 8 & 15 & 6 & 18 & 6 & 10 \\
\hline 8.00 & 35 & 28 & 24 & 20 & 14 & 10 & 17.5 & 7 & 21 & 8 & 14 \\
\hline 10.00 & 40 & 32 & 28 & 24 & 20 & 14 & 20 & 8 & 24 & 10 & 18 \\
\hline \multicolumn{12}{|c|}{ Bentonite mud treated with purple potato starch } \\
\hline 2.00 & 25 & 20 & 15 & 10 & 6 & 4 & 12.5 & 5 & 15 & 4 & 6 \\
\hline 4.00 & 27 & 22 & 16 & 12 & 8 & 6 & 13.6 & 6 & 15 & 6 & 8 \\
\hline 6.00 & 30 & 24 & 20 & 15 & 10 & 8 & 15 & 6 & 18 & 8 & 10 \\
\hline 8.00 & 36 & 28 & 24 & 20 & 15 & 10 & 18 & 8 & 20 & 10 & 14 \\
\hline 10.00 & 40 & 32 & 28 & 24 & 20 & 14 & 20 & 8 & 24 & 14 & 16 \\
\hline \multicolumn{12}{|c|}{ Bentonite mud treated with yellow potato starch } \\
\hline 2.00 & 30 & 24 & 20 & 15 & 10 & 5 & 15 & 6 & 18 & 5 & 10 \\
\hline 4.00 & 35 & 28 & 24 & 20 & 15 & 10 & 17.5 & 7 & 21 & 6 & 15 \\
\hline 6.00 & 40 & 32 & 28 & 24 & 20 & 15 & 20 & 8 & 24 & 8 & 20 \\
\hline 8.00 & 45 & 36 & 32 & 28 & 24 & 20 & 22.5 & 9 & 27 & 10 & 22 \\
\hline 10.00 & 50 & 40 & 36 & 32 & 28 & 24 & 25 & 10 & 30 & 12 & 24 \\
\hline \multicolumn{12}{|c|}{ Bentonite mud treated with saw dust } \\
\hline 2.00 & 15 & 12 & 10 & 6 & 4 & 4 & 7.5 & 3 & 9 & 2 & 4 \\
\hline 4.00 & 20 & 16 & 12 & 8 & 6 & 4 & 10 & 4 & 12 & 4 & 6 \\
\hline 6.00 & 22 & 18 & 14 & 10 & 8 & 6 & 11 & 4 & 12 & 6 & 8 \\
\hline 8.00 & 25 & 20 & 16 & 12 & 10 & 8 & 12.5 & 5 & 15 & 6 & 10 \\
\hline 10.00 & 30 & 24 & 20 & 15 & 12 & 10 & 15 & 6 & 18 & 8 & 12 \\
\hline
\end{tabular}




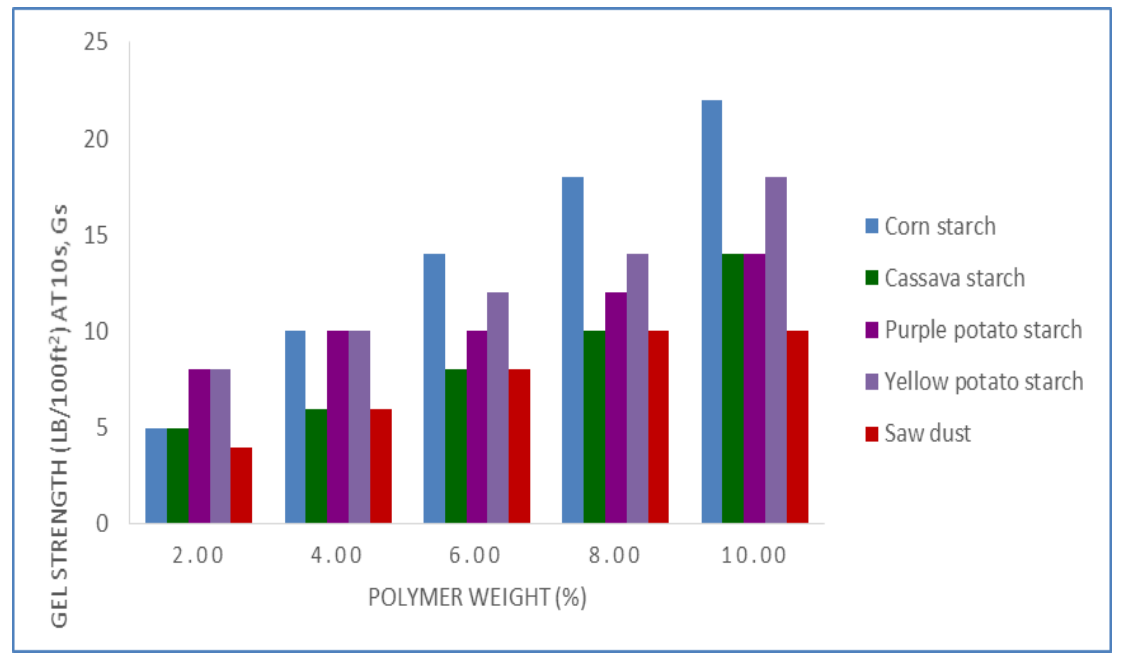

Figure 4 Effect of polymer concentration on the gel strength at 10s

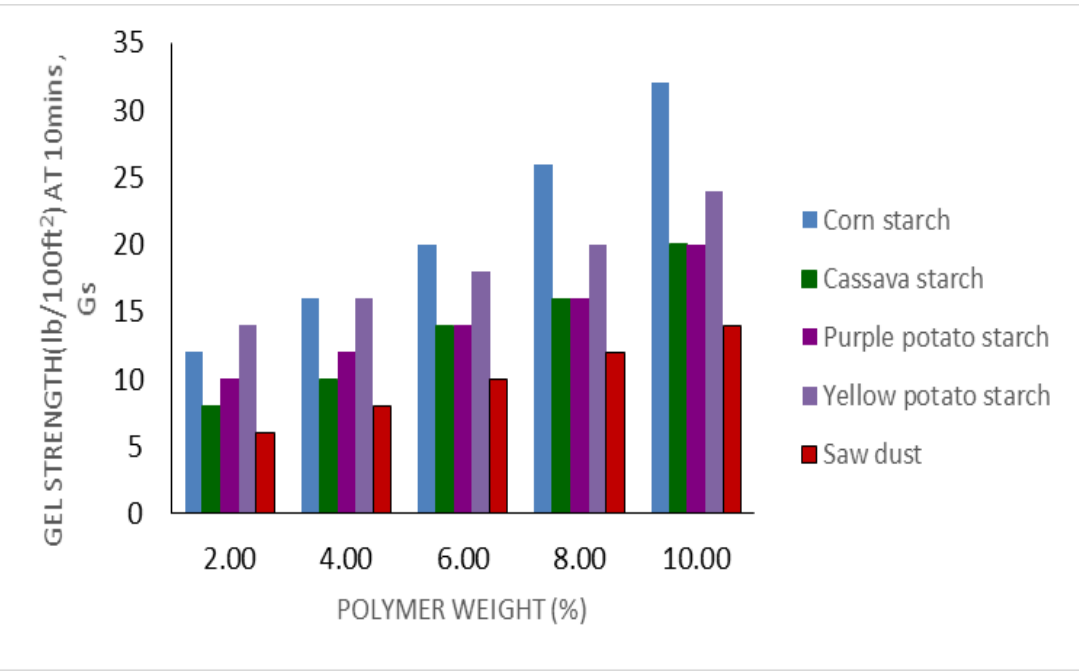

Figure 5 Effect of polymer concentration on the gel strength at 10 mins.

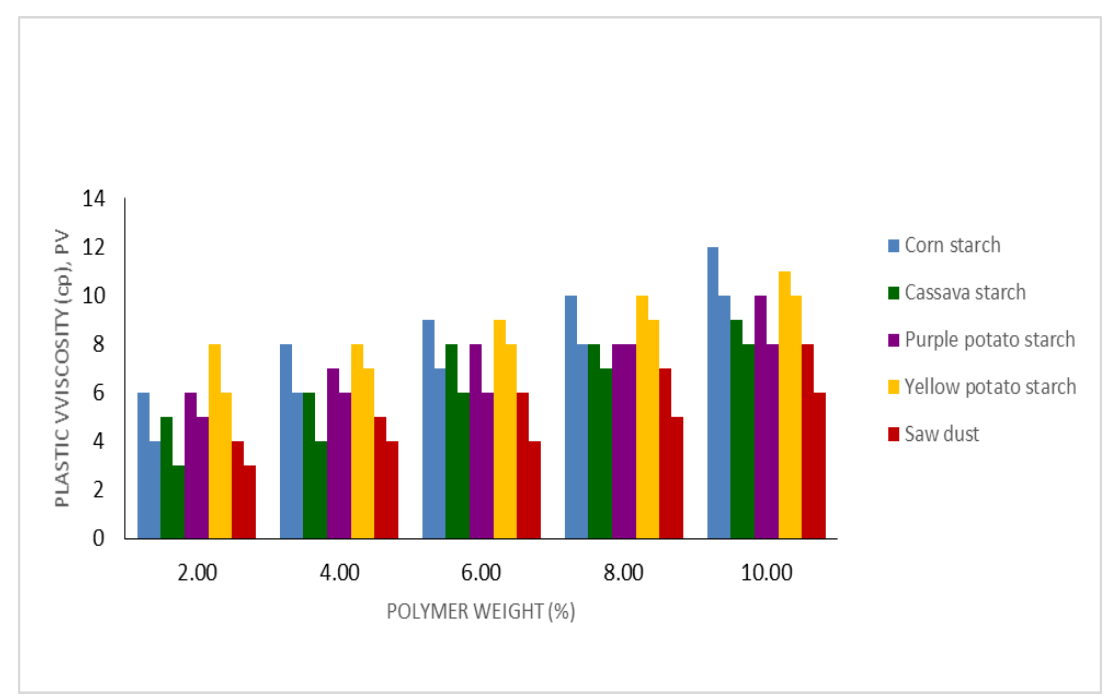

Figure 6 Effect of temperature on plastic viscosity of bentonite mud formulated with polymer at $100^{\circ} \mathrm{C}$ 


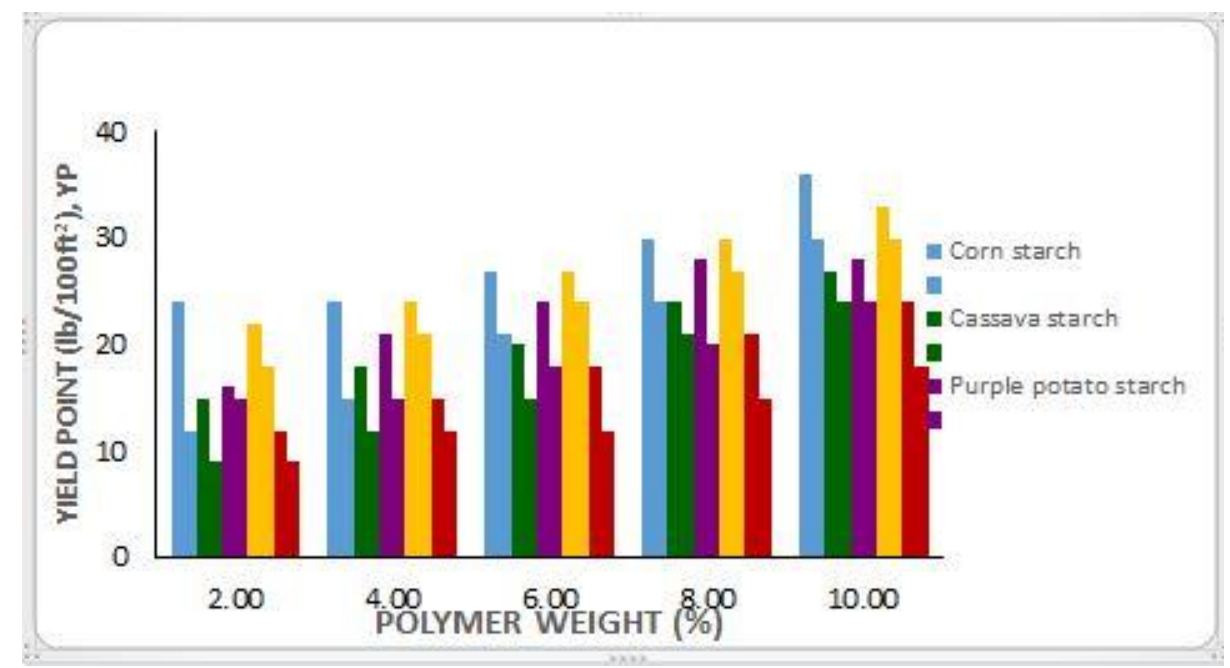

Figure $7 \mathrm{Effect}$ of temperature on yield point of bentonite mud formulated with polymer at $100^{\circ} \mathrm{C}$

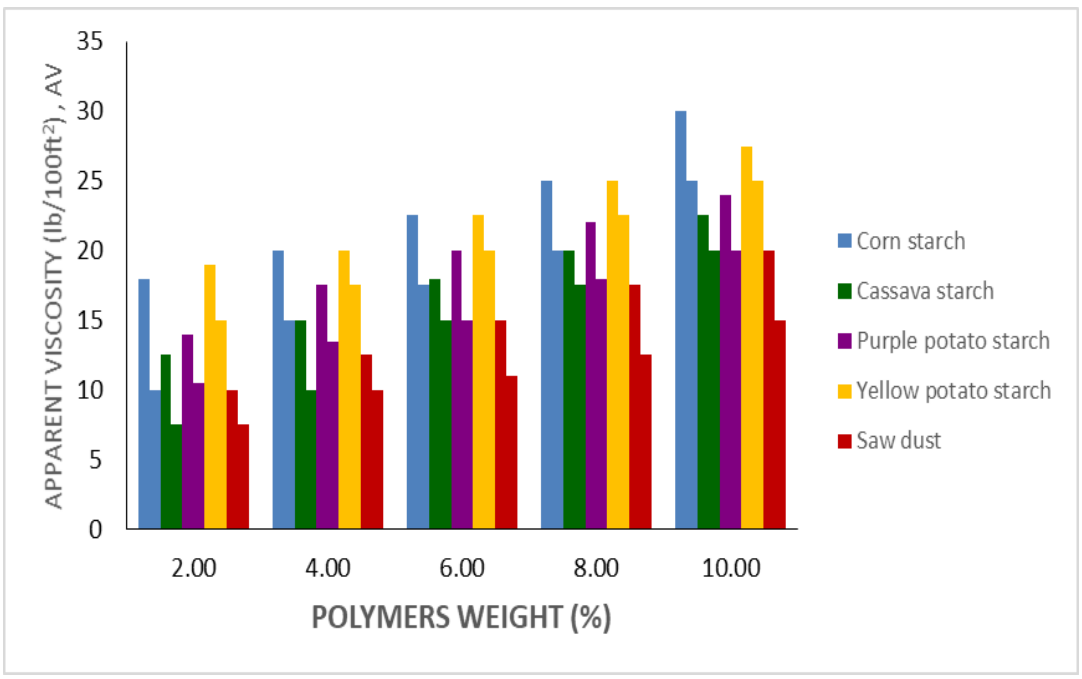

Figure 8 Effect of temperature on apparent viscosity of bentonite mud formulated with polymer at $100^{\circ} \mathrm{C}$

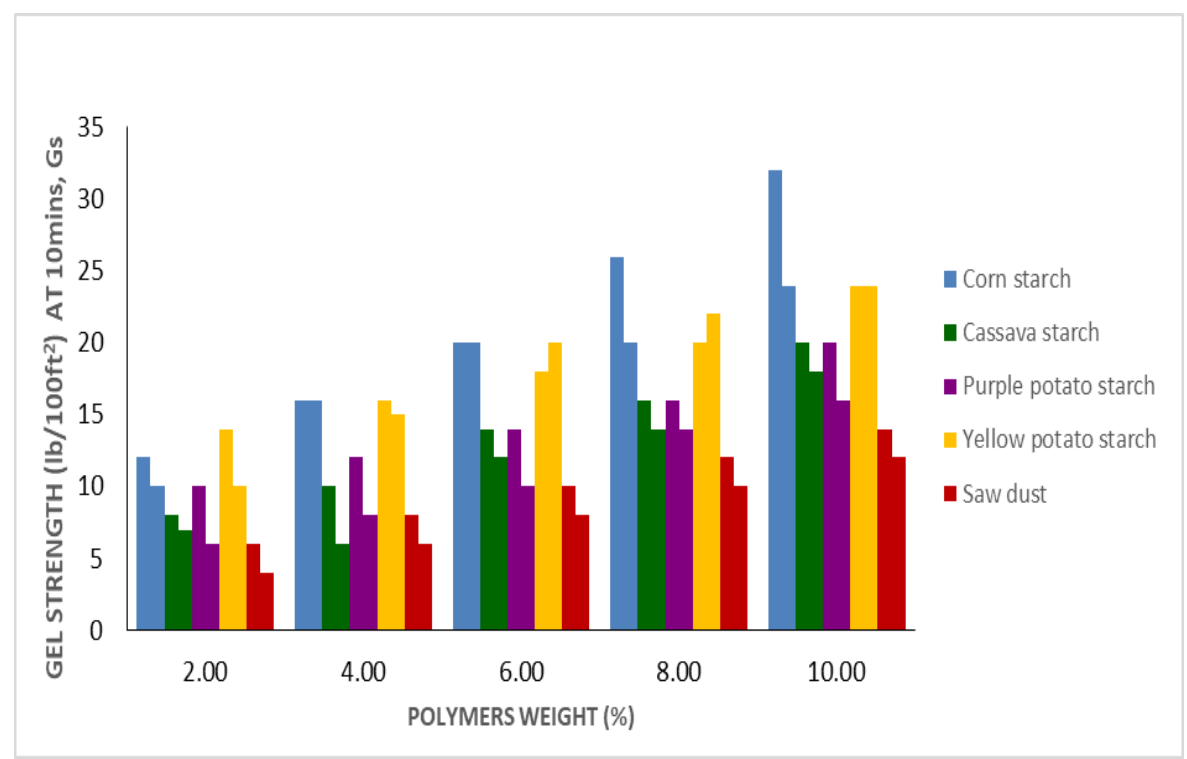

Figure 9 Effect of temperature on gel strength at 10 mins of bentonite mud formulated with polymer at $100^{\circ} \mathrm{C}$. 


\section{Conclusion}

Drilling muds have been formulated by employing locally derived materials made up of a mixture of locally selected starch from plants and bentonite which is readily available in commercial quantity as fluid loss additives and viscosifier. Furthermore, the influence of various additives on the performance of drilling fluid have been investigated with a bid to making the drilling operation smooth, cost effective and efficient. The selected polymers give sufficient rheological properties at ambient conditions and decrease in fluid loss with an increase in the concentration of polymers respectively. Bentonite muds give insufficient rheological properties at room condition. Corn starch and potato starch in comparison to other selected polymers showed notable improvement on apparent viscosity, plastic viscosity, yield point and gel strength at similar concentrations. High biodegradability of these starches however adversely affects their rheological properties. Therefore, the drilling time using the polymers should be as low as possible and biocide must be used to reduce the degradation rate. To control and enhance certain rheological properties of the bentonite drilling mud, with selected polymers, the concentration of the additives is very much a key element. Due to changes in the concentration of the locally selected polymers, significant changes were observed in the mud weight, plastic viscosity, yield point, apparent viscosity and gel strength.

\section{Compliance with ethical standards}

\section{Acknowledgments}

The authors would like to thank the MI-SWACO Mud Logging Laboratory at Onne Oil \& Gas Free Zone, Port Harcourt, Nigeria for the assistance rendered in carrying out the laboratory experiments.

\section{Disclosure of conflict of interest}

Both authors declare that they have no conflict of interest.

\section{References}

[1] Darley HCH, Gray GR. Composition and properties of Drilling and completion fluids fifth Edition, Houston, Texas Gulf Professional Publishing. 1983; 1-23.

[2] Hughes B. Drilling Fluids Principles. Reference Manual. 2006; 1-25.

[3] Jellison M, Chandler R, Payne M, Shepard J, Ultradeep drilling pushed drillstring technology innovations. SPE Drilling and Completion. 2008; 190-200.

[4] Shaughnessy J, Romo L, Soza R. Problems of ultra-deep high-temperature, high-pressure drilling. SPE Annual Technical Conference and Exhibition, Society of Petroleum Engineers. 2003.

[5] Suryanarayana PV, Bjorkevoll K. Design considerations for high-pressure/high-temperature wells. Advanced Drilling and Well Technology, Society of Petroleum Engineers. 2009.

[6] Iannuzzi, Environmentally assisted cracking EAC in oil and gas production. Woodhead Publishing Limited. 2011; 570-600.

[7] Ogiriki SO, Ndienye E. "Effect of Aging on water Based mud" International Journal of Engineering and modern technology. 2017; 3(5).

[8] Ogugbue CC, Shah SN. "Future challenges of drilling fluids and their rheological measurements" in American Association of Drilling Engineers fluids conference and exhibition, Houston, Texas. April 2010.

[9] Ademiluyi FT, Oduola K, Ogbonna FJ, Tubotamuno FH. Application of Starches from Selected Local Cassava Manihot Exculenta Crantz as Drilling Mud Additives. American Journal of Chemical Engineering. Special Issue: Oil Field Chemicals and Petrochemicals. 2017; 5(3-1): 10-20.

[10] Akinade A. Beneficiation of Nigeria local clay to meet API Standard Specification for drilling fluid formulation, A Case Study of ABBI Clay Deposit, International Journal of Engineering Sciences and management. 5: 14-28.

[11] Nyeche WE, Godwin JNC, Ifeoma PJ. “Drilling Mud Formulation Using Potato Starch Ipomoea Batatas”. Int. Journal of Engineering Research and Applications. 2015; 59: 48-54.

[12] Olatunde AO, Usman MA, Olafadehan OA., Adeosun TA, Ufot OE. Improvement of rheological properties of drilling fluid using locally based materials. Petroleum and Coal, 2012; 541: 65-75. 
[13] Oloro J. "Formulating Drilling Mud for troubled zone formation using locally sourced materials" International Journal of Advances in scientific research and engineering 2018; 4(1): 103-111.

[14] Omohimoria C, Falade A. "Comparative study of the Rheological Properties of local clay Afuze as a possible replacement for imported bentonite in drilling fluids formulation" International Journal of scientific and engineering Research. 2017; 8: 249-255.

[15] MISwaco, “Drilling Fluids Engineering Manual, Drilling Mud Laboratory”. Federal Ocean Terminal, Rivers State, Nigeria. 2019.

[16] Awele J. "Investigation of additives on drilling mud performance" Withtonder geothermal drilling as a case study, Master Degree Thesis, Department of Chemical Engineering, Aalborg University Denmark Esbjerg. 2014; $23-28$.

[17] National Driller. Properties of Water-based Muds, E-publishing by Army Corps of Engineers. 2007; 1-3.

[18] Aboulrous AA, Mahmoud IA, Ahmed MA, Tahany M. Application of Natural Polymers in Engineering, Production Department, Egyptian Petroleum Research Institute. Springer International Publishing Switzerland. 2015; 1-15.

[19] API, Specification for drilling-fluid materials, American Petroleum Institute, Houston, TX, Standard No. API 13A, 1995. 